\title{
Effects of acute sleep pattern alteration depend upon sleep duration
}

\author{
JOHN M. TAUB \\ University of Virginia Medical School, Charlottesville, Virginia 22901 \\ and \\ RALPH J. BERGER \\ University of California, Santa Cruz, California 95064
}

\begin{abstract}
The magnitude of the differences in performance, body temperature, and sleep stages following reduced, habitual, extended, and shifted sleep was compared in two groups of 10 healthy male university students who regularly slept nocturnally for 7-8 h or for 9.5-10.5 h. Measurements were obtained of sublingual temperature and from a 45-min Wilkinson auditory vigilance task $30 \mathrm{~min}$ after awakening in the morning, at midday, and in the evening following five electroencephalographically recorded nights of sleep. The experimental treatments comprised a habitual sleep condition and four conditions in which the regular sleep period was lengthened, reduced, delayed, and advanced by $3 \mathrm{~h}$. After all sleep conditions, the long sleepers compared with the control (7-8-h) group had a higher daily level of body temperature, less misses on the vigilance task, and shorter reaction times. As a result of the mean difference in total sleep time existing between groups, under all conditions the control subjects averaged less stage 2 and stage REM sleep, but more stage 4. Previous studies have shown that a 3-h advance or delay and a 3-h extension or reduction of established 7-8 $\mathrm{h}$ and 9.5-10.5-h sleep periods all result in generally equivalent degrees of impaired performance. The present findings indicate that $7-8 \mathrm{~h}$ sleepers were more impaired by acute alterations in the length and timing of sleep than habitual long sleepers.
\end{abstract}

The importance of obtaining an adequate amount of sleep and of maintaining a stable sleep-wakefulness cycle has been demonstrated by the findings of many recent studies (cf. review by Johnson \& Naitoh, Note 1). A situation of practical application which has recently been considered is the partial loss of sleep for one or more nights. In such studies, sleep has been restricted to $3 \mathrm{~h}$ per day over 8 days (Webb \& Agnew, 1965); to $5.5 \mathrm{~h}$ for 60 days (Webb \& Agnew, 1974b); fractionated into three 80 -min periods throughout the 24 -h period for 4 days (Hartley, 1974); reduced to $0,1,2,3$, 4, or $5 \mathrm{~h}$ over 2 days (Wilkinson, 1969, 1970; Wilkinson, Edwards, \& Haines, 1966); or $7.5,6$, or $4 \mathrm{~h}$ were permitted for 4 consecutive days (Hamilton, Wilkinson, \& Edwards, 1972, pp. 101-112). The effects of partial sleep loss have been found to be less than total sleep loss, and the magnitude of the adverse effect depends generally on the amount of sleep lost (Hamilton et al., 1972; Wilkinson, 1969). Losing $5.5 \mathrm{~h}$ of a single night's sleep caused subjects to miss more signals in an auditory

This research was supported in part by National Institute of Mental Health Grant MH-18928 and by National Institute of Mental Health Interdisciplinary Training Grant MH-06145. Computing assistance was obtained from the UCLA Health Sciences Computing Facility, sponsored by National Institute Special Research Resources Grant RR-3. Address correspondence and reprint requests to John M. Taub, Sleep and Dream Laboratory, University of Virginia Medical School, Department of Psychiatry, Charlottesville, Virginia 22901. signal detection task than did no sleep loss. Likewise, losing all of a night's sleep is worse than losing $5.5 \mathrm{~h}$ (Wilkinson, 1969).

Performance on vigilance and psychomotor tasks was as severely affected by extending sleep beyond habitual amounts in regular 7-8-h sleepers (Taub \& Berger, 1969; Taub, Globus, Phoebus, \& Drury, 1971) as is typically observed following partial or total sleep deprivation (Hamilton et al., 1972; Wilkinson, 1969; Wilkinson et al., 1966). Findings of studies in which the sleep of normal subjects has been extended (Taub et al., 1971; Verdone, 1968; Webb \& Agnew, 1974a, 1975b) indicate that the electrophysiological pattern of excess sleep is quite similar to the terminal portion of regular sleep. Thus, it is rather surprising that impaired behavior would result from extra sleep. In these studies, however, the sleep extension was imposed for only 1-3 days, so it is likely that extra sleep per se was not the single factor causing impaired behavior, but rather the acute effect of disrupting an adapted sleep-wakefulness routine (Taub \& Berger, 1973, 1974a, 1976a). The detrimental effects of lengthening or shortening sleep might be partially due to disruption of an established circadian rhythm of sleep and wakefulness, since changes in sleep duration necessarily involve alterations in times of sleep onset or awakening.

The regular temporal placement of sleep might, therefore, be equally important to any fixed amount of 
sleeping time for peak behavioral efficiency. In a previous study, we observed that performance and subjectively assessed mood declined during the day following acute 2-4-h advances and delays in the times when regular 12-8:00 a.m. sleepers were allotted their usual 7-8 h of sleep (Taub \& Berger, 1974a). As an extension of that experiment, the relative effects of extended sleep ( 9 p.m.-8 a.m.), reduced sleep (3-8 a.m.), and shifts of accustomed sleep (12-8 a.m.) time on subsequent performance and mood were examined (Taub \& Berger, 1973). Under the two conditions of shifting the subjects' habitual sleep in the circadian rhythm, the times allowed for sleep were 3-11 a.m. and 9 p.m. -5 a.m. such that times of retiring corresponded with either the extended sleep (9 p.m.) or reduced sleep (3 a.m.) treatments. This enabled the magnitude of differences between the effects of sleep length manipulation and shift of habitual sleep time to be compared. Lengthening or reducing sleep by $3 \mathrm{~h}$ caused behavioral deficits equivalent to advancing or delaying the regular sleep period by $3 \mathrm{~h}$.

Results from a more recent experiment (Taub \& Berger, 1976a) indicated that a 3-h advance or delay and a 3-h extension or reduction of an accustomed 9.5-10.5-h sleep period had similarly detrimental effects on perceptual-motor performance and subjectively assessed arousal as was previously observed following alterations in the length and timing of established 7-8-h sleep patterns. These findings imply that maintenance of accustomed sleep patterns is equal or greater in importance for the integrity of most waking functions than obtaining some invariant amount of sleep. The findings are, however, based upon acute sleep pattern variations, and it is unknown whether the effects of altering sleep pattern conditions would be similar as a function of individual differences in sleep behavior. Furthermore, before arriving at definitive conclusions on the relative importance of length and timing with regard to the human sleep requirement, the behavioral consequences of chronic sleep characteristics must be investigated.

In relation to sleep length, it would be both practically and theoretically significant to learn whether persons with characteristically different sleep duration patterns differed from each other behaviorally. If so, this would indicate the importance of obtaining a particular quota of sleep. On the other hand, if the null hypothesis of no behavioral differences was supported, perhaps this would suggest that sleep duration per se is relatively unimportant in relation to the maintenance of waking functions. A striking aspect of sleep length in a sample of a population at any age is the wide and consistent individual differences (Webb, 1971, pp. 149-176, 1972, pp. 31-46). Individual differences in total sleep times are likely to be of operational consequence when time for sleep is limited (Johnson \& Naitoh, Note 1). In few partial sleep loss studies, how- ever, has emphasis been placed on the large individual differences in the extent to which lack of sleep impairs performance (Wilkinson, 1961, 1970). For example, Williams and Williams (1966) have reported that the basic profile of nocturnal sleep psychophysiology was a valid predictor of the response to sleep loss. Restless sleepers with less Stage 4 sleep showed greater sleep-loss decrement following $64 \mathrm{~h}$ without sleep than did a quietsleep group. There is also evidence that would indicate a source of individuality in the capacity to sustain desynchronization of circadian rhythms (Lund, 1974) such as sleep-wakefulness.

It would be useful to define the maximum alteration in the length and timing of sleep (relative to the social norm) that can be sustained (cf. Hamilton et al., 1972, p. 101). But individual differences in sleep requirements will clearly render it difficult to substantiate this in the normal way. For the design of partial sleep loss experiments, Hamilton et al. (1972) proposed a deprivation ration calculated on the individual's normal sleep requirement as a solution to the problem. Acute sleep reduction, extended sleep, and phase shifts in sleep have been shown to produce deleterious behavioral effects (Taub \& Berger, 1973, 1974b, pp. 571-574, 1976b). The purpose of the present study was to compare the magnitude of differences produced by effects of shifting sleep time and altering sleep duration between long sleepers and regular 7-8-h sleepers studied previously under identical experimental designs (Taub \& Berger, 1973, 1976a).

\section{METHOD}

\section{Subjects}

Two groups of 10 male university students were selected as subjects. The subjects were initially screened with a modified version of the (CMI) Cornell Medical Index (Brodman, Erdmann, \& Wolff, 1956) and were considered for further study only if their responses to this inventory were not indicative of disturbed sleep, medical problems, psychiatric disorders, and frequent alcohol or other drug usage. Subjects selected at this stage in the screening procedure reported having consistently slept from 12-8:00 a.m. for 7-8 h or for $9.5 \mathrm{~h}$ or more over at least an immediately preceding period of 2 years.

Sleep charts were mailed to the remaining subjects with instructions to record for 2 weeks each 30-min period during which they were asleep. Subjects were eliminated if greàter than a 1-h discrepancy existed between their CMI estimate of sleep and their charted sleep during the 2 weeks. The charts of subjects considered acceptable showed that they usually retired at a habitual time and had 7-8 $\mathrm{h}$ or 9.5-10.5 $\mathrm{h}$ of uninterrupted sleep nightly with no evidence of unusual fluctuations or daytime naps. Finally, subjects were administered the MMPI and, in accordance with previously adopted criteria (Hartmann, Baekeland, \& Zwilling, 1972; Taub \& Berger, 1973), those who scored 2 SDs above normal on any MMPI scale except Mf [since elevated Mf (masculine-feminine) scales are now exceedingly common among young male university students] were rejected.

These procedures yielded 45 7-8-h sleepers and 17 long sleepers, from which the two groups of 10 subjects were randomly selected. Their ages ranged from 18 to 25 years and were similar in each group. The subjects all had a similar daily routine and none reported recent illness. 


\section{Measurement of Performance}

A 45-min Wilkinson (1970) auditory vigilance task was used as a measure of performance. Auditory vigilance has proven to be an aspect of behavior especially sensitive to moderate manipulation in sleep/waking patterns (Hamilton et al., 1972; Taub \& Berger, 1973, 1974a, 1976b; Wilkinson, 1969). Vigilance is a task that also shows decrement over time under normal conditions of wakefulness (Broadbent, 1971; Davies \& Tune, 1970; Deaton, Tobias, \& Wilkinson, 1971; Mackworth, 1969, 1970).

During testing, the subjects sat in a sound-attenuated cubicle and were presented the task binaurally through headphones. The auditory stimuli were $1 / 2$-sec tones occurring at 2 -sec intervals over $85 \mathrm{~dB}$ (SPL) ambient white noise. Thirty tones were slightly shorter than the others $(3 / 8 \mathrm{sec})$ and it was the subject's task to press a telegraph key immediately whenever he detected a short (critical) signal. The subjects' reaction times to the critical signals were recorded in $1-\mathrm{msec}$ units by a timer (Walker \& Nichparenko, 1972). The critical signals occurred at irregular intervals such that they seemed random to the subjects. Ten different audiotapes were used so that the order of signals remained unpredictable to the subjects throughout the experiment. The measures of performance used were the number of signals missed (misses) and incorrectly detected (false reports).

About 2-10 days before the experiment, the subjects practiced the task twice with at least $24 \mathrm{~h}$ intervening between the two sessions. During the first practice session, a 20-min instruction tape explained the vigilance task and provided practice. A 45-min test was then presented, preceded by a 3-min familiarization period during which the signals occurred frequently to remind the subjects of their perceptual characteristics. The second practice session consisted of another vigilance test tape.

\section{Design}

The experiment comprised five nights of sleep and an adaptation night of the subject's habitual 7-8-h or 9.5-10.5-h sleeping period preceded it by a week. The sleep treatments were presented in a 10 by 5 balanced incomplete block design and separated by a week to allow recovery from each. The five experimental treatments were as follows: habitual sleep; two conditions, one in which the sleep period was extended and another in which it was reduced by $3 \mathrm{~h}$; and two conditions, one in which the usual sleep period was advanced and another in which it was delayed by $3 \mathrm{~h}$.

The independent variables of sleep duration, retiring time, and awakening in the five conditions are depicted in Table 1. In the habitual condition, the subjects were allowed $7-8 \mathrm{~h}$ or 9.5-10.5 h of sleep at their accustomed hours. Under the extended sleep condition, the subjects accumulated extra sleep by retiring $3 \mathrm{~h}$ earlier than usual. In the sleep reduction condition, the subjects were required to remain awake $3 \mathrm{~h}$ later than usual. Time of retiring in the delayed-shift condition was the same as for sleep reduction, but subjects were awakened $3 \mathrm{~h}$ later; in the advanced-shift condition, it corresponded to that in the extended sleep condition, but subjects were awakened $3 \mathrm{~h}$ earlier. In both shifted-sleep conditions, the subjects were thereby allotted their usual amount of sleep. Testing times were scheduled relative to subjects' habitual sleep patterns as follows: (a) after awakening, (b) before lunch, at midday, and (c) in the early evening.

\section{Procedure}

The subjects were instructed not to nap or to drink caffeinated beverages, but to maintain their usual physical activity and food and fluid intake throughout the experiment. They were told that the study concerned the relationship between sleep and personality functioning. The subjects reported to the laboratory between 6 and 6:30 p.m., and sat in bed reading magazines or books with all external time cues eliminated, including daylight, chronometers, and radios, until after postsleep testing. This was done in order to equate energy expenditures during waking and sleeping as closely as possible.

Electrodes were placed for recording electroencephalogiaphic (EEG), electromyographic, and electrooculographic activity during all conditions, and the records were scored for sleep stages by $30-\sec$ epochs according to standard procedures (Rechtschaffen \& Kales, 1968). The first sleep spindle was used to identify sleep onset (cf. Agnew \& Webb, 1972; Johnson, 1973; Snyder \& Scott, 1972, pp. 645-708). Recordings from the habitual, advanced-, and delayed-shift sleep conditions were coded and scored blind with respect to treatment. Sleep records from the extended and reduced sleep conditions differed markedly in duration so that a blind scoring procedure was not feasible. Upon awakening, the subjects were served $120 \mathrm{ml}$ of fruit juice as a partial nutritional control for blood sugar level.

Thirty minutes later, they were given the vigilance task, which was administered again in similar order the same day before lunch and in the early evening. Sublingual temperature was recorded by clinical thermometer for $5 \mathrm{~min}$ at the end of each testing session. There were no cues present in the experimental setting or from the experimenter to inform subjects about their performance.

\section{RESULTS}

One-way ANOVAs were computed to determine the overall magnitude of the differences following the

Table 1

Independent Variables of Retiring and Awakening Times in the Habitual, Reduced, Extended, and Shifted Sleep Conditions for the Two Subject Groups

\begin{tabular}{|c|c|c|c|c|c|}
\hline $\begin{array}{c}\text { Independent } \\
\text { Variables }\end{array}$ & $\begin{array}{l}\text { Reduced } \\
\text { Sleep }\end{array}$ & $\begin{array}{c}\text { Delayed } \\
\text { Shift }\end{array}$ & $\begin{array}{c}\text { Habitual } \\
\text { (H) }\end{array}$ & $\begin{array}{c}\text { Advanced } \\
\text { Shift }\end{array}$ & $\begin{array}{l}\text { Extended } \\
\text { Sleep }\end{array}$ \\
\hline & \multicolumn{5}{|c|}{ 7-8-h Group } \\
\hline $\begin{array}{l}\text { Sleep duration } \\
\text { Retiring time } \\
\text { Awakening time }\end{array}$ & $\begin{array}{l}5 \mathrm{~h} \\
\text { 3:00 a.m. } \\
\text { 8:00 a.m. }\end{array}$ & $\begin{array}{l}8 \mathrm{~h} \\
\text { 3:00 a.m. } \\
\text { 11:00 a.m. }\end{array}$ & $\begin{array}{c}8 \mathrm{~h} \\
\text { 12:00 a.m. } \\
\text { 8:00 a.m. } \\
\text { 9.5-10.5-h Group }\end{array}$ & $\begin{array}{l}8 \mathrm{~h} \\
\text { 9:00 p.m. } \\
\text { 5:00 a.m. }\end{array}$ & $\begin{array}{l}11 \mathrm{~h} \\
\text { 9:00 p.m. } \\
\text { 8:00 a.m. }\end{array}$ \\
\hline $\begin{array}{l}\text { Sleep duration } \\
\text { Retiring time } \\
\text { Awakening time }\end{array}$ & $\begin{array}{l}6.5-7.5 \mathrm{~h} \\
3 \mathrm{~h} \text { later } \\
\text { than } \mathrm{H} \\
\text { Same as } \mathrm{H}\end{array}$ & $\begin{array}{l}9.5-10.5 \mathrm{~h} \\
3 \mathrm{~h} \text { later } \\
\text { than } \mathrm{H} \\
3 \mathrm{~h} \text { later } \\
\text { than } \mathrm{H}\end{array}$ & $9.5-10.5 \mathrm{~h}$ & $\begin{array}{c}9.5-10.5 \mathrm{~h} \\
3 \mathrm{~h} \text { earlier } \\
\text { than } \mathrm{H} \\
3 \mathrm{~h} \text { earlier } \\
\text { than } \mathrm{H}\end{array}$ & $\begin{array}{l}12.5-13.5 \mathrm{~h} \\
3 \mathrm{~h} \text { earlier } \\
\text { than } \mathrm{H} \\
\text { Same as } \mathrm{H}\end{array}$ \\
\hline
\end{tabular}




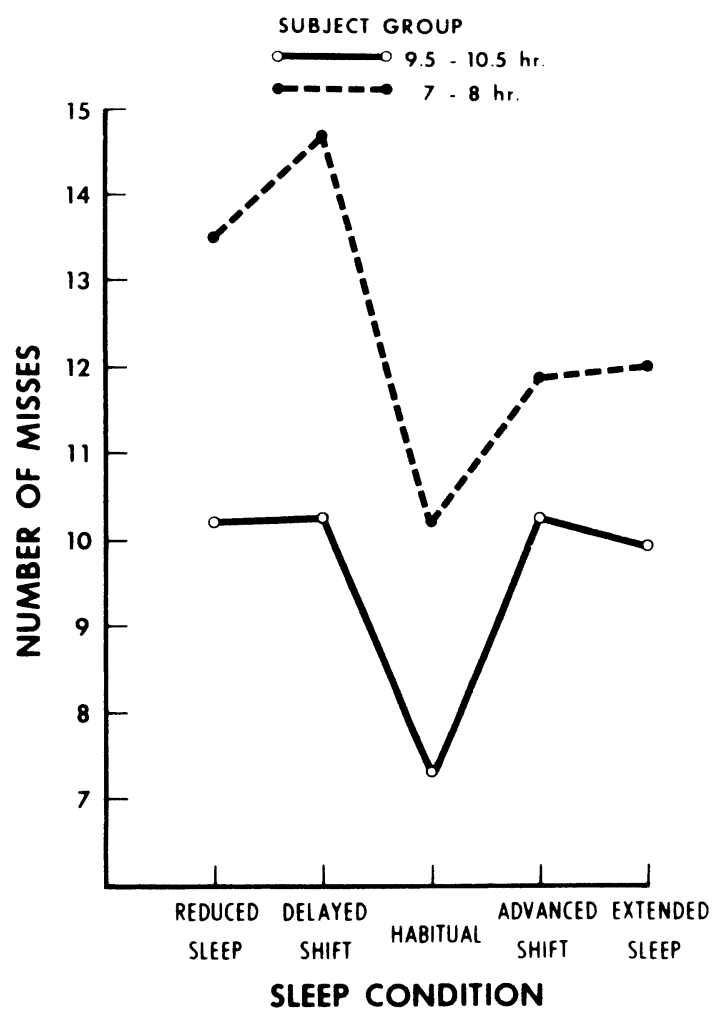

Figure 1. Misses on the vigilance task after nights of habitual, reduced, extended, and shifted sleep.

reduced, habitual, extended, and shifted sleep conditions between the 7-8-h and 9.5-10.5-h subject groups on body temperature, performance, and sleep staging. All $\mathrm{F}$ ratios were based upon 1 and $18 \mathrm{df}$.

\section{Performance and Body Temperature}

Following the procedure adopted in previous studies (Hamilton et al., 1972; Taub \& Berger, 1974b; Wilkinson, 1969, 1970; Wilkinson et al., 1966), performance and body temperature were averaged from the three testing sessions. Differences in mean levels of these variables throughout the day between the two groups were then compared. The mean daily levels of speed and accuracy on the vigilance task and body temperature following the five sleep conditions differed in the two subject groups. These differences between the habitual long sleepers and control group in body temperature and performance were statistically significant. ${ }^{1}$

Figure 1 shows the mean number of misses for each sleep condition and the two subject groups. Misses were less after all sleep conditions for the long sleepers compared with the control group $(\mathrm{F}=9.55, \mathrm{p}<.01)$. There were no significant between-group differences evident for false reports. With low levels of false alarm rate, the measure is rather unreliable and has a large within-subjects variance (cf. Hamilton et al., 1972).
Mean reaction time to critical signals on the vigilance task for each sleep condition and the two groups is shown in Figure 2. It can be seen that after all sleep conditions, long sleepers had shorter reaction times than the controls $(F=7.89, p<.025)$.

Figure 3 shows that the trend of oral temperature closely paralleled that of performance. In the long sleepers, the mean daily value of body temperature following sleep was higher than for the 7-8-h group, $(\mathrm{F}=12.60, \mathrm{p}<.005)$.

\section{Sleep Variables}

The long sleepers differed significantly from the control group in total time slept $(F=39.94, p<.001)$ (Figure 4). Total sleep time which did not differ significantly between the advanced-shift, delayed-shift, or habitual sleep conditions averaged $9 \mathrm{~h}$ for the long sleepers and $7 \mathrm{~h}$ for the control group. In the reduced sleep condition, the long sleepers averaged $6.2 \mathrm{~h}$ and the control subjects averaged $4.8 \mathrm{~h}$. On nights of extended sleep, the mean total sleep time for long sleepers was $11.3 \mathrm{~h}$ and for the control group $9.3 \mathrm{~h}$.

Sleep stages in the various conditions for the long sleepers and control subjects are presented in Figure 5. The principal differences in sleep patterns between groups were in Stage 2, Stage 4, and REM sleep. The long sleepers had greater absolute amounts of Stage 2

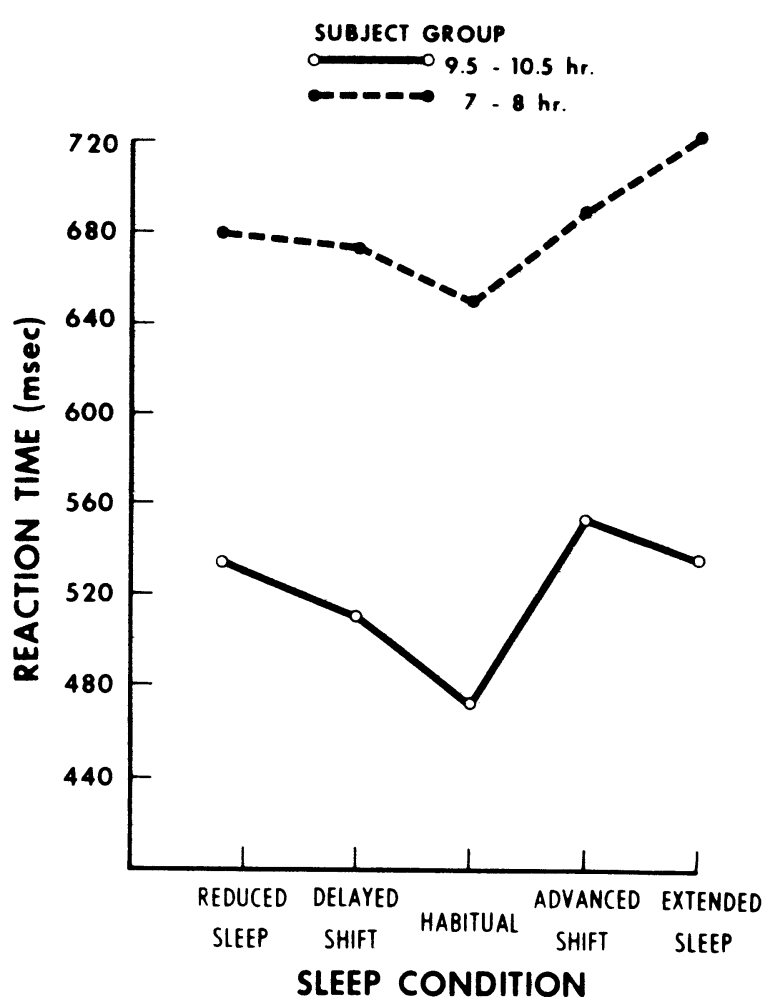

Figure 2. Reaction time to signals on the vigilance task after nights of habitual, reduced, extended, and shifted sleep. 


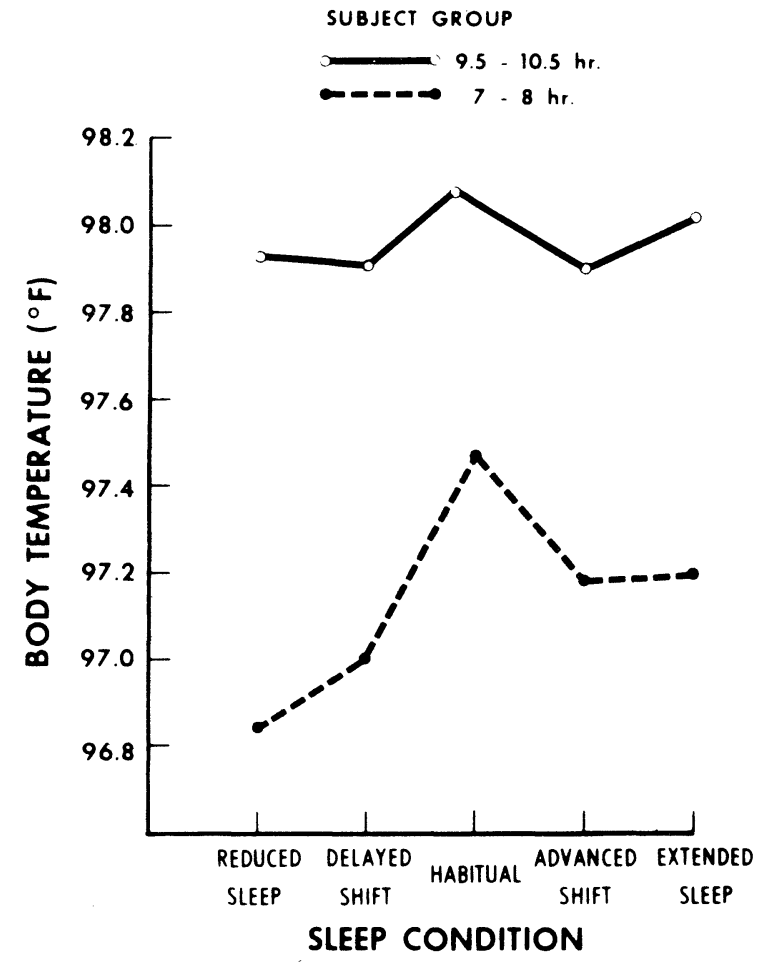

Figure 3. Mean daily level of sublingual temperature after nights of habitual, reduced, extended, and shifted sleep.

$(\mathrm{F}=44.36, \mathrm{p}<.001)$, more REM sleep $(\mathrm{F}=15.52$, $\mathrm{p}<.001)$, but less Stage $4(\mathrm{~F}=7.95, \mathrm{p}<.025)^{2}$

Stages 1 and 3 were almost equal between groups.

\section{DISCUSSION}

Previous studies have shown (Taub \& Berger, 1973, 1974a, b, 1976a, b) that a 3-h advance or delay and a 33-h extension or reduction of established 7-8-h and 9.5-10.5-h sleep periods all result in generally equivalent
SUBJECT GROUP

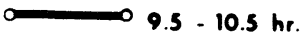

$\sim-\infty-8 \mathrm{hr}$

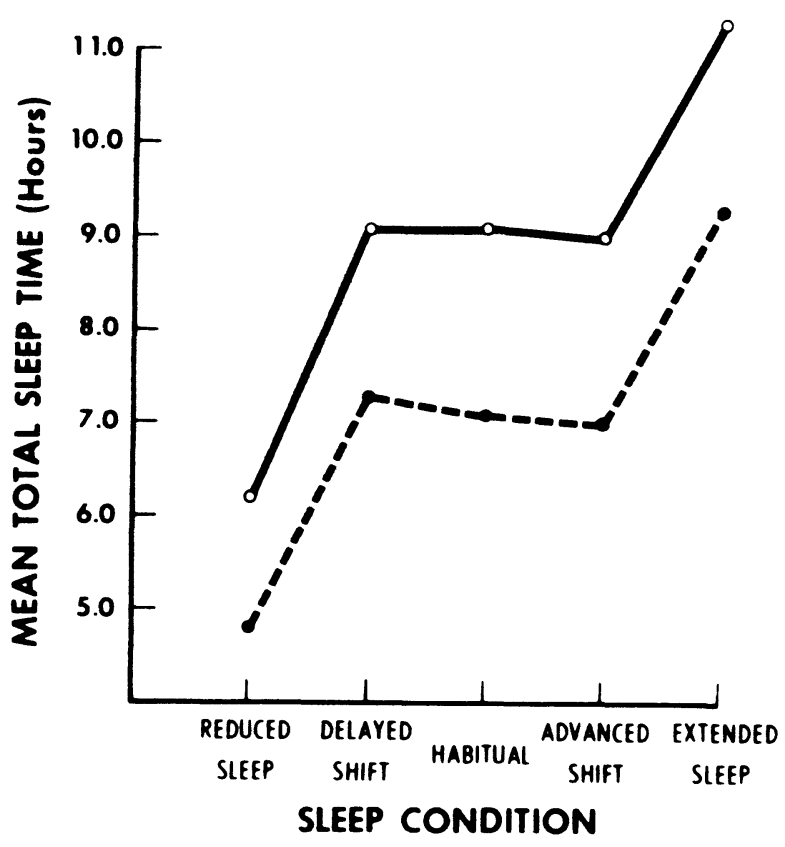

Figure 4. Total time spent asleep during nights of habitual, reduced, extended, and shifted sleep.

degrees of impaired performance. The present findings further indicate that 7-8-h sleepers were more impaired by acute alterations in the length and timing of sleep than habitual long sleepers. These subjects, selected on the basis of naturally occurring 7-8-h and 9.5-10.5-h sleep patterns, also showed evident differences in behavioral efficiency even following baseline or habitual sleep and in EEG sleep stage characteristics, as well. Correspondingly, by the statistical analysis of baseline nocturnal EEG profiles, Williams and Williams (1966)
Figure 5. Amounts of time spent in each sleep stage during nights of habitual, reduced, extended, and shifted sleep.
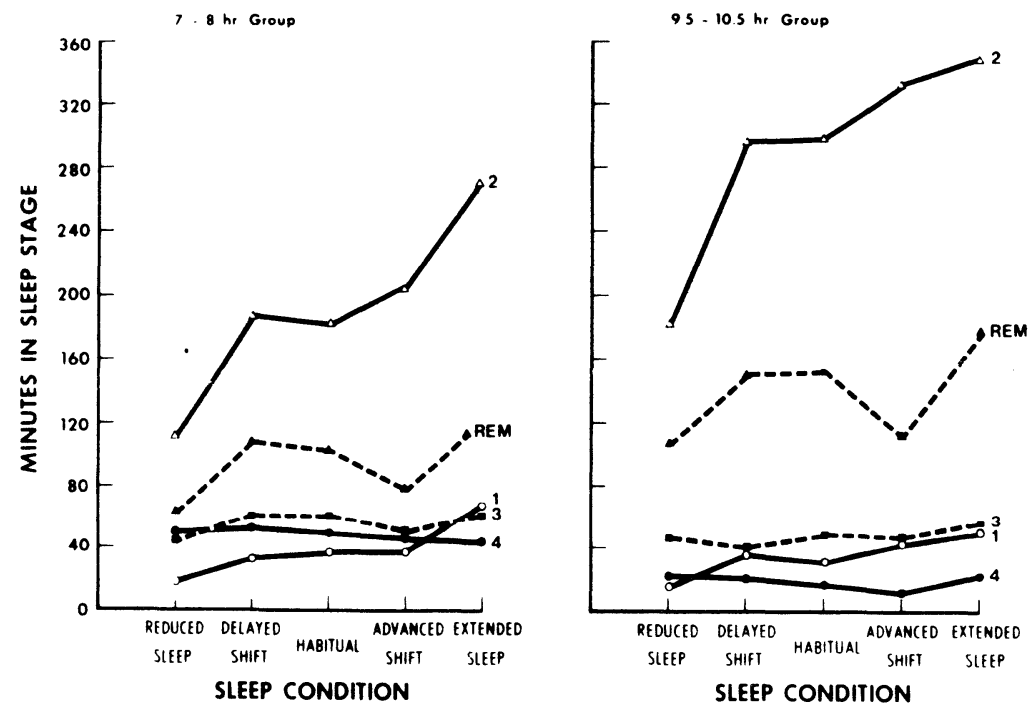
identified two groups of subjects (restless and quiet) who differed in their performance efficiency under acute sleep deprivation. Restless sleepers with delayed sleep onset, reduced slow-wave sleep, frequent waking, frequent body movements, and frequent transition from stage to stage showed greatest sleep-loss decrement. Both the amount and type of sleep a subject characteristically has appear to be significant determinants of the response to alterations in the length and timing of sleep.

Daily levels in performance have not been previously compared between individuals who sleep different amounts, as in the present study. Hartmann, Baekeland, Zwilling, and Hoy (1971), did, however, compare the performance of long and short sleepers on a $30-\mathrm{min}$ Wilkinson (1970) vigilance task for 6 consecutive nights after their normal length of sleep. No significant differences were observed between groups, and since this task is especially sensitive to sleep loss, it was concluded (Hartmann et al., 1971) that the short sleepers had not become sleep-deprived during successive nights in the laboratory. Marked daily variations are exhibited in perception, biochemistry, and physiology (Luce, 1971), and in the instance of vigilance, values vary so greatly throughout the day (Colquhoun, 1971, pp. 39-108; Hockey \& Colquhoun, 1972, pp. 1-24) that data obtained at a single time point are difficult to interpret (see, e.g., Nichols \& Tyler, 1967). Of course, it may well be that habitual long and short sleepers do not differ in performance efficiency and that performance decrements are only present in studies where sleep durations are acutely shifted from the habitual amount. The difference in performance between natural long sleepers and $7-8$-h sleepers of the present study must be subtle, for it was even observed following baseline sleep.

Body temperature and sensorimotor performance were lower in the control subjects than in the long sleepers. These same physiological and behavioral measures which differentiated subject groups as a function of sleep duration are also sensitive indicators of sleep deprivation. There is an overall decrease during a period of sleep loss in body temperature (Johnson, Slye, \& Dement, 1965; Kleitman \& Jackson, 1950; Kollar, Pasnau, Rubin, Naitoh, Slater, \& Kales, 1969; Murray, Williams, \& Lubin, 1958; Naitoh, Pasnau, \& Kollar, 1971), and in performance on prolonged auditory vigilance (Lubin, Moses, Johnson, \& Naitoh, 1974; Wilkinson, 1969) and reaction time (Bohlin \& Kjellberg, 1973; Lisper \& Kjellberg, 1972). Body temperature is regarded (Colquhoun, 1971; Hockey \& Colquhoun, 1972) as a comprehensive index of organismic arousal and correlates closely with psychomotor performance (Blake, 1967; Bohlin \& Kjellberg, 1973; Schubert, 1969). Correspondingly, physiological indicators such as blood pressure, heart rate, oral temperature, and performance all tend to show a similar pattern of decline with sleep loss (see, e.g., Saito, 1972). The present results demonstrated that performance measures and body tempera- ture differed between groups in a consistent way. Therefore, it could be postulated that this pattern is evidence of a decrease in activation (Ax \& Luby, 1961; Corcoran, 1964) attributable to chronic subclinical sleep deprivation in the 7-8-h control subjects (see, e.g., Webb \& Agnew, 1975a).

Aserinsky (1973) computed a ratio to statistically represent the maximal sleep which can be accumulated by a person in $24 \mathrm{~h}$ without diminishing the amount obtainable in a subsequent 24-h period. The values he derived, based upon continuous electrophysiological recordings of subjects who attempted sleeping to fullest capacity for $54 \mathrm{~h}$, ranged from $8.4 \mathrm{~h}$ to $11.8 \mathrm{~h}$ and compare remarkably with the lowest value for the long sleepers of $8.5 \mathrm{~h}$ in the habitual condition to $11.8 \mathrm{~h}$, the most sleep accumulated during the extended condition. The concentration of eye movements during REM periods, which has been construed (Aserinsky, 1969) as an index of sleep satiety, approaches a maximum value with 7.5-h-10.5-h sleep. If REM density is accepted as reflecting the satisfaction of a sleep need, then for subjects in the control group whose habitual sleep averaged slightly above $7 \mathrm{~h}$, sleep satiety was probably not achieved as a normal condition.

For the long sleepers, in the habitual condition, mean values for total sleep time and Sleep Stages 1, REM, and 2 are very close to those presented by Webb and Agnew (1970) in a normative study of high school seniors, who characteristically slept $8.5 \mathrm{~h}$ or more. The results further demonstrate that sleep duration is a factor operative in influencing sleep psysiology (Agnew \& Webb, 1973; Aserinsky, 1973; Verdone, 1968; Webb, 1973 b, pp. 256-258), whereby Stage REM is concentrated in the later phase of the sleep period and Stage 2 is essentially linearly distributed across the night (Webb $\&$ Agnew, 1975a). As a result of the differences in total sleep time existing between groups, control subjects averaged less Stage 2 and Stage REM.

One could contend that there were behavioral deficits in the control group attributable to selective (e.g., REM) sleep deprivation which raises the question as to whether each of these sleep stages serves a unique restorative function. Present evidence (cf. reviews by Johnson, 1973; Webb, 1973a, pp. 176-184) indicates that the amount of sleep (Wilkinson, 1969) is more crucial than the specific stage of sleep for maintaining waking functions (Johnson, 1973; Johnson, Naitoh, Lubin, \& Moses, 1972, pp. 81-100; Johnson, Naitoh, Moses, \& Lubin, 1974; Lubin et al., 1974; Moses, Johnson, Naitoh, \& Lubin, 1975). For example, patients on phenelzine, a monoamine oxidase inhibitor, and without REM sleep (Akindele, Evans, \& Oswald, 1970; Wyatt, Fram, Buchbinder, \& Snyder, 1971), persons without Stage 4 (Natani, Shurley, Pierce, \& Brooks, 1970), and those above age 40 who have decreased amounts of Stage 4 (Feinberg, 1974; Feinberg \& Carlson, 1968; Webb \& Agnew, 1969) all appear to function quite effectively 
(cf. Johnson et al., 1974). Subjects deprived of Stage 4 or REM sleep during $8 \mathrm{~h}$ of recovery sleep following complete sleep loss (Lubin et al., 1974) showed no significant difference on vigilance or memory tasks and measures of mood. It would therefore appear quite plausible to assume that relatively less efficiency in the 7-8-h control group was a general consequence of reduced total sleep time per se.

The EEG recordings of the long sleepers contained an amount of Stage 4 significantly below that in the control group, being also somewhat lower than generally reported values. Stage 4 was entirely absent in 5 of the nights involving two of these subjects and varied considerably between subjects, as indicated by the large standard deviations. The mean number of minutes of Stage 4 observed in the present study for the long sleepers over all conditions averaged almost $30 \mathrm{~min}$ less than the corresponding value for the control group and 54 min less compared with the reported value in younger subjects not as extreme in their patterns of long sleep (Webb \& Agnew, 1970). The wide variability for reported values of Stage 4 (Clausen, Sersen, \& Lidsky, 1974) and the large ranges at all age groups quite possibly reflect as yet undelineated factors that fluctuate with age and among individuals (Webb \& Agnew, 1971). The quantities of Stage 4 in the long sleepers remained constant across nights, so that it is likely to have represented a stable trait of the subjects (cf. Clausen et al., 1974).

\section{CONCLUSION}

Differences in the susceptibility of subjects to performance decrement after acute sleep reduction, extended sleep, and sleep cycle phase shifts have been demonstrated. These findings emphasize the importance of controlling for individual differences in sleep patterns even when evaluating the effects of comparatively moderate perturbations in the sleep-wakefulness cycle. If it is known that altered sleep duration or sleep period time displacements are inevitable, from the present findings, at least, it could be predicted that natural long sleepers will perform more effectively than 7-8-h sleepers. Supportive evidence across an experimental paradigm comprising studies of characteristically long sleepers (Taub \& Berger, 1976a, b) and regular 7-8-h sleepers (Taub \& Berger, 1973) has shown that generally similar behavioral deficits resulted from shifting sleep and altering sleep length within each subject group. Furthermore, even with a mean total sleep time of $4.65 \mathrm{~h}$ separating sleep reduction and extension conditions in both experiments, few substantially different effects on subsequent waking behavior were observed. The findings of similar effects resulting from shifting sleep and altering sleep length within groups of subjects is not consistent with the differences which have been shown between the 7-8-h and 9.5-10.5-h sleepers.
Although such differences in performance efficiency were observed, it is not possible to derive any causative explanation for the findings. Further experimental operations to delimit the levels of efficiency associated with sleep duration might involve the adaptation of persons to prolonged modifications in sleep patterns (see, e.g., Webb \& Agnew, 1974b) as, for example, a chronic increase in sleep length for 7-8-h sleepers and/or chronic limitation in sleep for long sleepers.

\section{REFERENCE NOTE}

1. Johnson, L. C., \& Naitoh, P. The operational consequences of sleep deprivation and sleep deficit. San Diego: Navy Medical Neuropsychiatric Research Unit, 1974.

\section{REFERENCES}

AgneW, H. W., \& WeBb, W. B. Measurement of sleep onset by EEG criteria. American Journal of EEG Technology, 1972, 12, 127-134.

Agnew, H. W., \& WebB, W. B. The influence of time course variables on REM sleep. Bulletin of the Psychonomic Society, 1973, 2, 131-133.

Akindele, M. O., Evans, J. I., \& Oswald, I. Mono-amine oxidase inhibitors, sleep and mood. Electroencephalography and Clinical Neurophysiology, 1970, 29, 47-56.

Aserinsky, E. The maximal capacity for sleep: Rapid eye movement density as an index of sleep satiety. Biological Psychiatry, 1969, 1, 147-159.

AsERINSKy, E. Relationship of rapid eye movement density to the prior accumulation of sleep and wakefulness. Psychophysiology, $1973,10,545-558$.

Ax, A., \& LuBY, E. D. Autonomic responses to sleep deprivation. Archives of General Psychiatry, 1961, 4, 55-59.

BLAKE, M. J. F. Time of day effects on performance in a range of tasks. Psychonomic Science, 1967, 9, 349-350.

Bohlin, G. A., \& KJellberg, A. Self-reported arousal during sleep deprivation and its relation to performance and physiological variables. Scandinavian Journal of Psychology, 1973, 14, 78-86.

Broadbent, D. E. Decision and stress. New York: Academic Press, 1971.

Brodman, K., Erdmann, A., \& Wolff, H. Cornell medical index health questionnaire manual. New York: Cornell University Medical College, 1956.

Clausen, J., Sersen, A., \& Lidsky, A. Variability of sleep measures in normal subjects. Psychophysiology, 1974, 11, 509-516.

Colquhoun, W. P. Circadian variations in mental efficiency. In W. P. Colquhoun (Ed.), Biological rhythms and human performance. New York: Academic Press, 1971.

Corcoran, D. W. J. Changes in heart rate and performance as a result of loss of sleep. British Journal of Psychology, 1964, 55, 307-314.

Davies, D. R., \& Tune, G. S. Human vigilance performance. London: Staples Press, 1970.

Deaton, M., Tobias, J., \& Wilkinson, R. T. The effect of sleep deprivation on signal detection parameters. Quarterly Journal of Experimental Psychology, 1971, 23, 449-452.

FEINBERG, I. Changes in sleep cycle patterns with age. Journal of Psychiatric ${ }^{-R e s e a r c h, ~ 1974, ~ 10, ~ 283-306 . ~}$

Feinberg, I., \& Carlson, V. R. Sleep variables as a function of age in man. Archives of General Psychiatry, 1968, 18, 239-250. 
Hamilton, P., Wilkinson, R. T., \& Edwards, R. S. A study of four days partial sleep deprivation. In W. P. Colquhoun (Ed.), Aspects of human efficiency. London: English Universities Press, 1972.

Hartley, L. R. A comparison of continuous and distributed reduced sleep schedules. Quarterly Journal of Experimental Psychology, 1974, 26, 8-14.

Hartmann, E., Baekeland, F., \& Zwilling, G. Psychological differences between long and short sleepers. Archives of General Psychiatry, 1972, 26, 463-468.

Hartmann, E., Baekeland, F., Zwilling, G., \& Hoy, P. Sleep need: How much sleep and what kind? American Journal of Psychiatry, 1971, 127, 41-48.

Hockey, G. R. J., \& Colquhoun, W. P. Diurnal variation in human performance: A review. In W. P. Colquhoun (Ed.), Aspects of human efficiency. London: English Universities Press, 1972.

Johnson, L. C. Are stages of sleep related to waking behavior? American Scientist, 1973, 61, 326-338.

Johnson, L., Naitoh, P., Lubin, A., \& Moses, J. Sleep stages and performance. In W. P. Colquhoun (Ed.), Aspects of human efficiency. London: English Universities Press, 1972.

Johnson, L. C., Naitoh, P., Moses, J. M., \& Lubin, A. Interaction of REM deprivation and stage 4 deprivation with total sleep loss: Experiment 2. Psychophysiology, 1974, 11, 147-159.

Johnson, L. C., Slye, E. S., \& Dement, W. Electroencephalographic and autonomic activity during and after prolonged sleep deprivation. Psychosomatic Medicine, 1965, 27, 415-423.

KLeitman, N., \& JACKson, D. P. Body temperature and performance under different routines. Journal of Applied Physiology, 1950, 3, 309-328.

Kollar, E. J., Pasnau, R. O., Rubin, R. T., Naitoh, P., Slater, G. G., \& Kales, A. Psychological, psychophysiological and biochemical correlates of prolonged sleep deprivation. American Journal of Psychiatry, 1969, 126, 488-497.

LisPER, H., \& KJELlBERG, A. Effects of 24-hour sleep deprivation on rate of decrement in a 10 -minute auditory reaction time task. Journal of Experimental Psychology, 1972, 96, 287-290.

Lubin, A., Moses, J., Johnson, L. C., \& Naitoh, P. The recuperative effects of REM sleep and stage 4 sleep on human performance after complete sleep loss: Experiment 1. Psychophysiology, 1974, 11, 133-146.

LUCE, G. G. Body time: Physiological rhythms and social stress. New York: Pantheon, 1971.

Lund, R. Personality factors and desynchronization of circadian rhythms. Psychosomatic Medicine, 1974, 36, 224-228.

MACKWORTH, J. F. Vigilance and habituation. Middlesex, England: Penguin, 1969.

MACKWORTH, J. F. Vigilance and attention. Middlesex, England: Penguin, 1970.

Moses, J. M., Johnson, L. C., Nattoh, P., \& Lubin, A. Sleep stage deprivation and total sleep loss: Effects on sleep behavior. Psychophysiology, 1975, 12, 141-146.

MurRay, E. J., Williams, H. L., \& Lubin, A. Body temperature and psychological ratings during sleep deprivation. Journal of Experimental Psychology, 1958, 56, 271-273.

Naitoh, P., Pasnau, R. O., \& Kollar, E. J. Psychophysiological changes after prolonged deprivation of sleep. Biological Psychiatry, 1971, 3, 309-320.

Natani, K., Shurley, J. T., Pierce, C. M., \& Brooks, R. E. Long-term changes in sleep patterns in men on the South Polar Plateau. Archives of Internal Medicine, 1970, 125, 655-659.

Nichols, C. T., \& TYLER, F. H. Diurnal variation in adrenal cortical function. Annual Review of Medicine, 1967, 18, 313-324.

Rechtschaffen, A., \& Kales, A. (Eds.). A manual of standardized terminology, techniques, and scoring system for sleep stages of human subjects. Washington, D.C: U.S. Government Printing Office, 1968.
SAITo, Y. Specification of variation patterns of physiological and performance measurements in sleep loss. Journal of Human Ergology, 1972, 1, 207-216.

SCHUBERT, D. S. P. Simple task rate as a direct function of diurnal sympathetic nervous system predominance; a law of performance. Journal of Comparative and Physiological Psychology, 1969, 68, 434-436.

SIEGEL, S. Non-parametric statistics for the behavioral sciences. New York: McGraw-Hill, 1956.

SNYDER, F., \& Scotr, J. The psychophysiology of sleep. In N. S. Greenfield \& R. A. Sternbach (Eds.), Handbook of psychophysiology. New York: Holt, Rinehart, \& Winston, 1972.

TAUb, J. M., \& BERgER, R. J. Extended sleep and performance: The Rip Van Winkle effect. Psychonomic Science, 1969, 16, 204-205.

TAUB, J. M., \& Berger, R. J. Performance and mood following variations in the length and timing of sleep. Psychophysiology, $1973,10,559-570$.

TAUB, J. M., \& BERGER, R. J. Acute shifts in the sleep-wakefulness cycle: Effects on performance and mood. Psychosomatic Medicine, 1974, 36, 164-173. (a)

TAUB, J. M., \& BERGER, R. J. Effects of acute shifts in circadian rhythms of sleep and wakefulness on performance and mood. In L. E. Scheving, F. Halberg, \& J. E. Pauly (Eds.), Chronobiology: Proceedings of the International Society for the Study of Biological Rhythms. Tokyo: Igaku Shoin, 1974. (b)

TAUB, J. M., \& BERGER, R. J. Altered sleep duration and sleep period time displacements: Effects on performance in habitual long sleepers. Physiology and Behavior, 1976, 16, 177-184. (a)

TAUB, J. M., \& BERgER, R. J. The effects of changing the phase and duration of sleep. Journal of Experimental Psychology: Human Perception and Performance, 1976, 2, 30-41. (b)

Taub, J. M., Globus, G. G., Phoebus, E., \& Drury, R. Extended sleep and performance. Nature, 1971, 233, 663-664.

Verdone, P. Sleep satiation: Extended sleep in normal subjects. Electroencephalography and Clinical Neurophysiology, 1968, 24, 417-423.

Walker, J. M., \& Nichparenko, W. A general purpose timer/counter. Perceptual and Motor Skills, 1972, 35, 707-710.

WeBB, W. B. Sleep as a biorhythm. In W. P. Colquhoun (Ed.), Biological rhythms and human performance. London: Academic Press, 1971.

WEBB, W. B. Patterns of sleep behaviour. In W. P. Colquhoun (Ed.), Aspects of human efficiency. London: English Universities Press, 1972.

WEBB, W. B. Selective and partial deprivation of sleep. In W. P. Koella (Ed.), Sleep: Physiology, biochemistry, psychology, pharmacology, clinical implications. Basel: Karger, 1973. (a)

WEBB, W. B. The different functional relationships of REM and stage 4 sleep. In U. J. Jovanovic (Ed.), The nature of sleep. Stuttgart: Fischer, 1973. (b)

WebB, W. B., \& AGNEW, H. W. Sleep: Effects of a restricted regime. Science, $1965,150,1745-1747$.

WebB, W. B., \& AgNew, H. W. Measurement and characteristics of nocturnal sleep. Progress in Clinical Psychology, 1969, 8, 2-27.

WEBB, W. B., \& AGNEW, H. W. Sleep stage characteristics of long and short sleepers. Science, 1970, 168, 146-147.

WebB, W. B., \& AGNEW, H. W. Stage 4 sleep: Influence of time course variables. Science, 1971, 174, 1354-1356.

WebB, W. B., \& AGNew, H. W. Sleep and waking in a time-free environment. Aerospace Medicine, 1974, 44, 617-622. (a)

WEBB, W. B., \& AGNEW, H. W. The effects of a chronic limitation of sleep length. Psychophysiology, 1974, 11, 265-274. (b)

WeBb, W. B., \& AGNEW, H. W. Are we chronically sleep deprived? Bulletin of the Psychonomic Society, 1975, 6, 47-48. (a)

WEBB, W. B., \& AGNEW, H. W. Effects on subsequent sleep of an acute restriction in sleep length. Psychophysiology, 1975, 12, 367-370. (b) 
Wilkinson, R. T. Interaction of lack of sleep with knowledge of results, repeated testing, and individual differences. Journal of Experimental Psychology, 1961, 62, 263-271.

Wilkinson, R. T. Sleep deprivation: Performance tests for partial and selective sleep deprivation. Progress in Clinical Psychology, 1969, 8, 28-43.

WiLkinson, R. T. Methods for research on sleep deprivation and sleep function. International Psychiatry Clinics, 1970, 7, 369-381.

Wilkinson, R. T., Edwards, R. S., \& Haines, E. Performance following a night of reduced sleep. Psychonomic Science, 1966, 5, 471-472.

Williams, H. L., \& Williams, C. L. Nocturnal EEG profiles and performance. Psychophysiology, 1966, 3, 164-175.

Wyatt, R. J., Fram, D. H., Buchbinder, R., \& SNyder, F. Treatment of intractable narcolepsy with a monoamine oxidase inhibitor. New England Journal of Medicine, 1971, 285, 987-991.

\section{NOTES}

1. All $F$ tests were checked with the Kruskal-Wallis one-way analysis of variance (Siegel, 1956, pp. 184-193). A result is reported as statistically significant only when the two tests agreed.

2. Paralleling results of the overall ANOVAs were significant differences at the .05 level or better following the individual sleep conditions between groups on body temperature, performance, and the sleep measures using two-tailed values of the Mann-Whitney U-test.

(Received for publication March 11, 1976; revision accepted June 30,1976 .) 